\title{
Phytochemicals, Antioxidants, and Cholinesterase Inhibitory Profiles of Elatostema Papillosum Leaves: An Alternative Approach for Management of Alzheimer's Disease
}

\author{
A. S. M. Ali Reza', Mst. Samima Nasrin', A. H. M. Khurshid Alam² \\ 'Department of Pharmacy, Faculty of Science and Engineering, International Islamic University, Chittagong, Bangladesh \\ ${ }^{2}$ Department of Pharmacy, University of Rajshahi, Bangladesh
}

\section{Article Info}

\section{Article Notes}

Received: August 1, 2018

Accepted: October 8, 2018

\section{${ }^{*}$ Correspondence:}

Dr. A. H. M. Khurshid Alam, Professor, Department of

Pharmacy, University of Rajshahi, Rajshahi-6205, Bangladesh E-mail: khurshid.jaist@gmail.com.

(c) 2018 Khurshid Alam AHM. This article is distributed under the terms of the Creative Commons Attribution 4.0 International License

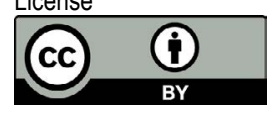

\section{Keywords:}

Alzheimer's disease

Antioxidant

Phytochemicals and Oxidative stress

\section{ABSTRACT}

Alzheimer's disease (AD) is a devastating neurodegenerative disorder of the brain characterized by memory loss and, impaired judgment and language use. As $A D$ incidence increases with age, $A D$ has become a large socioeconomic burden that will only continue growing as populations age. Natural compounds that possess polyphenolic (phenolics and flavonoids) content and antioxidant property have the capacity to reduce the progression and symptoms of neurodegenerative diseases, including $A D$. In this mini-review, we emphasize the pathomechanisms of $A D$, including oxidative stress and modulatory roles of natural antioxidants in preventing AD. We discuss the antioxidant, phytochemical, and anticholinesterase properties of the plant Elatostema papillosum, which are relevant to the management of AD.

\section{Introduction}

Alzheimer's disease (AD) is a neurodegenerative disorder of the brain characterized by memory dysfunction, impairment in language and judgment capacity. $\mathrm{AD}$ is the most common cause of presenile and senile dementia worldwide ${ }^{1}$. In 2006, 26.6 million AD patients were diagnosed; this is expected to rise to 106.8 million by $2050^{2}$. The prevalence rate of $\mathrm{AD}$ doubles every five to ten years and this incidence increases exponentially with age, rising from $3 \%$ among those $65-$ 74 , to almost $50 \%$ among those 85 or older ${ }^{3}$. Thus, dementia and $A D$ have become primary areas of research due to their enormous social, economic, and health care impacts. Indeed, after cancer and coronary heart disease, $\mathrm{AD}$ is the third most expensive disorder in the United States; moreover, total worldwide societal costs were estimated to be $\$ 315$ million in 2005 , with about $70 \%$ of costs occurring in developed countries ${ }^{4}$.

The etiology of $\mathrm{AD}$ is not yet completely understood. However, both genetic and environmental factors are responsible for late-onset and sporadic $\mathrm{AD}^{5}$, with aging being the greatest risk factor for $\mathrm{AD}^{6}$. The apolipoprotein $\mathrm{E}$ (ApoE) genotype is the second greatest risk factor for $\mathrm{AD}$ after age. ApoE has three isoforms ApoE2, ApoE3, and ApoE4. Among the isoforms, ApoE4 is the most common and least protective variant of $\mathrm{AD}^{7,8}$. Two other important factors linked to $\mathrm{AD}$ are the overproduction of $A \beta$ protein and abnormal tau protein. Kuszczyk et al., (2009) and Scheff et al., (2007) reported that the highly-phosphorylated tau protein and overproduction of $A \beta$ protein initiate the loss of neurons, neuropil, and synaptic elements ${ }^{9}, 10$, which leads to cognitive function deficiencies and dementia. It is believed that accumulation of extracellular $A \beta$ protein plays a central role in the pathogenesis of AD. The mechanism of 
$\mathrm{A} \beta$ formation is complex, but several studies suggest that enhanced oxidative stress provoked by $A \beta$ is associated with $\mathrm{AD}^{11}$.

\section{Oxidative stress and Alzheimer's disease}

Antioxidants are molecules involved in scavenging reactive species, which can be caused by oxidative stress (OS). Antioxidants have a wide range of effects in various disease conditions and can help to prevent onset and progression of certain diseases. OS is emerging as a key mechanism underlying the pathogenesis of $\mathrm{AD}$ in both human brains and animal models, alongside excess deposition of $A \beta$ protein, neurofibrillary tangle (NFT) formation, and metabolic dysfunction ${ }^{12-14}$. The relationship between systemic $\mathrm{OS}$ and $\mathrm{AD}$ has received increased recognition in the last decade ${ }^{8}$. In addition, accumulation of intracellular free radicals dysfunctions the activities or expressions of antioxidant enzymes superoxide dismutase (SOD) and catalase, have also been described in the brain of a patient diagnosed with $\mathrm{AD}^{15}$. Moreover, oxidative damage can occur in peripheral cells as well as neuronal cells when oxidative homeostasis is disturbed; the resultant excessive production of reactive oxygen damages the cellular antioxidant defense mechanisms and triggers the occurrence of $\mathrm{AD}^{8}$.

There are a number of sources of OS in AD patients, including increased levels of iron-redox-active state in NFT as well as in $A \beta$ protein ${ }^{16}$, activated microglia surrounded by the most senile plaques, which produce $\mathrm{NO}$ and $\mathrm{O}_{2}$ -17. Amyloid- $\beta$ protein precursor (A $\beta P P$ ) responsible for formation of reactive oxygen ${ }^{18}$, abnormalities in the mitochondrial genome ${ }^{8}$, and deficiencies in key metabolic enzymes ${ }^{19}$. Reactive oxygen species (ROS) are those that include reactive oxygen ions and peroxides and cause detrimental effects at high concentration to all biomolecules (DNA, RNA, proteins and lipids), leading to pathological conditions in humans ${ }^{18}$. The imbalance between cellular production of ROS and the inability of cells to defend against ROS causes OS, which contributes to age-related neurodegeneration and cognitive decline ${ }^{8}$.

Antioxidants as a Therapeutic Target in Alzheimer's Disease

Antioxidants play a functional role in the pathogenesis of the different diseases, including AD. Therefore, diverse antioxidants $\mathrm{N}$-acetylcysteine, curcumin, resveratrol, vitamin $\mathrm{E}$, vitamin $\mathrm{C}$, ferulic acid, coenzyme $\mathrm{Q}$ (CoQ), selenium, and melatonin, have been tested for their protective role in cognitive performance in both healthy individuals, as well as those with mild cognitive impairment and $\mathrm{AD}^{20}$. However, despite promising effects of these compounds on cellular oxidative status in vitro and in vivo, the realistic evidence of their therapeutic potential in humans is limited. Recently, Mazzanti et al., reviewed a number of published and ongoing clinical trials with the use of curcumin and resveratrol for AD therapy ${ }^{21}$. Moreover, Morris et al., (2002) and Engelhart et al., (2002) reported that eating foods rich in antioxidants such as beta carotene and vitamins $\mathrm{C}$ and $\mathrm{E}$ are associated with lower risk of $\mathrm{AD}$ and dementia ${ }^{22,23}$. Furthermore, under normal conditions, OS and cellular damage are combated by endogenous antioxidant compounds and enzymes. However, the brain is highly vulnerable to oxidative damage due to high levels of ROS and poor antioxidant systems.

In addition, ROS-mediated mitochondrial damage plays a key role in $\mathrm{AD}$ pathogenesis. Therefore, agents that target mitochondrial dysfunctions and reverse oxidative stress may serve as novel AD therapeutics. One such therapeutic might be MitoVitE, also known as mitotocopherol, which protects mitochondria from oxidative stress via inhibition of lipid peroxidation ${ }^{8}$. Pocernich et al., (2011) reported that in both $\mathrm{AD}$ and mild cognitive deficit brains with significantly decreased levels of antioxidant enzymes, the brains became vulnerable to deposition of $A \beta$ protein ${ }^{24}$. Consequently, it was suggested that one way of enhancing brain defense was by improving the antioxidant defense system, particularly endogenous glutathione (GSH), glutathione-related enzymes, catalase, and superoxide dismutase.

\section{Elatostema papillosum and Alzheimer's Disease Treatment}

Agents which elevate acetylcholine (ACh) levels are essential targets for AD treatment. ACh is an organic neurotransmitter found in the synapses of the cerebral cortex. Decreased levels of ACh and insufficient cholinergic function have been correlated with cognitive deficits seen in $\mathrm{AD}$ patients ${ }^{25}$. Therefore, several strategies have been established to increase ACh levels, such as using the ACh precursor (choline) ${ }^{26}$, muscarinic and nicotinic agonists ${ }^{27}$, $\mathrm{ACh}$ releasers ${ }^{28}$, and acetylcholinesterase (AChE) inhibitors ${ }^{29}$. Among these, the acceptable option for AD treatment is restoration of ACh levels through inhibition of two major forms of cholinesterase enzymes, AChE and butrylcholinesterase $(\mathrm{BChE})^{29}$. To date, only three cholinesterase inhibitors, donepezil, galantamine and rivastigmine have been approved by the US Food and Drug administration to treat $\mathrm{AD}^{30}$. However, these compounds have been reported to have therapeutic activity along with adverse side effects, such as hepatotoxicity, short duration of biological action, low bioavailability, and gastrointestinal disturbances ${ }^{31}$. Therefore, natural sources, especially plants have been gaining attention for putative use as novel cholinesterase inhibitors and/or antioxidants.

Elatostema papillosum (E. papillosum), a member of Urticaceae family, is a suberect herb (commonly known as Elya) available in Australia and Oceania, China, Bhutan, India, and Bangladesh. From existing ethnobotanical 
literature, it is clear that E. papillosum has marked folkloric reputation as useful in combatting different afflictions, such as hysteria and abdominal pain ${ }^{32}$. Interestingly, some characteristics of hysteria overlap with symptoms of $\mathrm{AD}^{33}$. Recently, many research groups have reported that antioxidant-enriched plants and plant metabolites possess remarkable cholinesterase inhibition capacity ${ }^{12,13,34}$. Our group also reported that E. papillosum showed marked cholinesterase inhibition and free radical (DPPH and hydroxyl radical) scavenging activities. Furthermore, the plant possessed potent phenolic and flavonoid content along with a positive correlation between antioxidant and cholinesterase inhibition potential ${ }^{14}$. Recent evidence suggests that the secondary metabolites, flavonoids, have positive effects against dementia and $\mathrm{AD}^{35-37}$. Our results were consistent with those of the data published previously ${ }^{12,13,34}$ and suggest that E. papillosum may be a valuable method for treating $\mathrm{AD}$ by targeting both the OS and impaired cholinergic signaling characteristic of $A D$.

\section{Conclusions}

Medicinal plants having potential antioxidant and free radical scavenging capacity can be applied to reduce dementia and to treat AD. Polyphenolic compounds are the most abundant antioxidants in the plant kingdom harboring neuroprotective effects. As, E. papillosum is a significant source of phenolics and flavonoids, which act as natural cholinesterase inhibitors and free radical scavengers, this plant may be a powerful future medicine for treating and managing $\mathrm{AD}$.

\section{Acknowledgement}

The authors are grateful to the Department of Pharmacy, International Islamic University Chittagong, Bangladesh for providing necessary facilities for this research work. The authors also thank Mr. John Vaughen, a native English speaker, for his critical comments and language correction.

\section{References}

1. Ferri CP, Prince M, Brayne $C$, et al. Global prevalence of dementia: a Delphi consensus study. Lancet. 2005; 366(9503): 2112-2117.

2. Brookmeyer R, Johnson E, Ziegler-Graham K, et al. Forecasting the global burden of Alzheimer's disease. Alzheimers dement. 2007; 3(3): 186-191.

3. Zhu CW, Sano M. Economic considerations in the management of Alzheimer's disease. Clin interv aging. 2006; 1(2): 143.

4. Wimo A, Winblad B, Jönsson L. An estimate of the total worldwide societal costs of dementia in 2005. Alzheimers dement. 2007; 3(2): 81-91.

5. Rosenberg RN, Lambracht-Washington D, Yu G, et al. Genomics of Alzheimer disease: a review. Jama neurol. 2016; 73(7): 867-874.

6. Hebert LE, Weuve J, Scherr PA, et al. Alzheimer disease in the United States (2010-2050) estimated using the 2010 census. Neurology. 2013; 80(19): 1778-1783.

7. Mahoney-Sanchez L, Belaidi AA, Bush AI, et al. The complex role of apolipoprotein $\mathrm{E}$ in Alzheimer's disease: an overview and update. J mol neurosci. 2016; 60(3): 325-335.
8. Wojsiat J, Zoltowska KM, Laskowska-Kaszub K, et al. Oxidant/ Antioxidant Imbalance in Alzheimer's Disease: Therapeutic and Diagnostic Prospects. Oxid med cell longev. 2018; 2018.

9. Kuszczyk M, Gordon-Krajcer W, Lazarewicz JW. Homocysteine-induced acute excitotoxicity in cerebellar granule cells in vitro is accompanied by PP2A-mediated dephosphorylation of tau. Neurochem int. 2009; 55(1-3): 174-180.

10. Scheff S, Price D, Schmitt F, et al. Synaptic alterations in CA1 in mild Alzheimer disease and mild cognitive impairment. Neurology. 2007; 68(18): 1501-1508.

11. Zhang L, Yu H, Zhao X, et al. Neuroprotective effects of salidroside against beta-amyloid-induced oxidative stress in SH-SY5Y human neuroblastoma cells. Neurochem int. 2010; 57(5): 547-555.

12. Uddin MN, Afrin R, Uddin MJ, et al. Vanda roxburghii chloroform extract as a potential source of polyphenols with antioxidant and cholinesterase inhibitory activities: identification of a strong phenolic antioxidant. BMC complement altern med. 2015; 15(1): 195.

13. Asaduzzaman M, Uddin MJ, Kader M, et al. In vitro acetylcholinesterase inhibitory activity and the antioxidant properties of Aegle marmelos leaf extract: implications for the treatment of Alzheimer's disease. Psychogeriatrics. 2014; 14(1): 1-10.

14. Reza AA, Hossain MS, Akhter S, et al. In vitro antioxidant and cholinesterase inhibitory activities of Elatostema papillosum leaves and correlation with their phytochemical profiles: a study relevant to the treatment of Alzheimer's disease. BMC complement altern med. 2018; 18(1): 123.

15. Chen Z, Zhong C. Oxidative stress in Alzheimer's disease. Neurosci bull. 2014; 30(2): 271-281.

16. Honda K, Casadesus G, Petersen RB, et al. Oxidative stress and redoxactive iron in Alzheimer's disease. Ann N Y acad sci. 2004; 1012(1): 179-182.

17. Unger MS, Marschallinger J, Kaindl J, et al. Doublecortin expression in CD8+ T-cells and microglia at sites of amyloid- $\beta$ plaques: A potential role in shaping plaque pathology. Alzheimers dement. 2018.

18. Bonda DJ, Wang X, Perry G, et al. Oxidative stress in Alzheimer disease: a possibility for prevention. Neuropharmacology. 2010; 59(4-5): 290294.

19. Parker WD, Filley CM, Parks JK. Cytochrome oxidase deficiency in Alzheimer's disease. Neurology. 1990; 40(8): 1302-1302.

20. Di Domenico F, Barone E, Perluigi M, et al. Strategy to reduce free radical species in Alzheimer's disease: an update of selected antioxidants. Expert rev neurother. 2015; 15(1): 19-40.

21. Mazzanti G, Di Giacomo S. Curcumin and resveratrol in the management of cognitive disorders: what is the clinical evidence. Molecules. 2016; 21(9): 1243.

22. Morris MC, Evans DA, Bienias JL, et al. Dietary intake of antioxidant nutrients and the risk of incident Alzheimer disease in a biracial community study. Jama. 2002; 287(24): 3230-3237.

23. Engelhart MJ, Geerlings MI, Ruitenberg A, et al. Dietary intake of antioxidants and risk of Alzheimer disease. Jama. 2002; 287(24): 3223-3229.

24. B Pocernich C, LB Lange M, Sultana R, et al. Nutritional approaches to modulate oxidative stress in Alzheimer's disease. Curr. alzheimer res. 2011; 8(5): 452-469.

25. Ali SK, Hamed AR, Soltan MM, et al. In-vitro evaluation of selected Egyptian traditional herbal medicines for treatment of Alzheimer disease. BMC complement altern med. 2013; 13(1): 121.

26. Dolmella A, Bandoli G, Nicolini M. Alzheimer's disease: a pharmacological challenge. Adv drug res. 1994; 25: 203-294. 
27. Greenlee W, Clader J, Asberom T, et al. Muscarinic agonists and antagonists in the treatment of Alzheimer's disease. Farmaco. 2001; 56(4): 247-250.

28. Wesseling H, Agoston S, Van Dam G, et al. Effects of 4-aminopyridine in elderly patients with Alzheimer's disease. N engl j med. 1984; 310(15): 988.

29. Villarroya M, Garcia A, Marco J. New classes of AChE inhibitors with additional pharmacological effects of interest for the treatment of Alzheimer's disease. Curr pharm des. 2004; 10(25): 3177-3184.

30. Massoud F, Gauthier S. Update on the pharmacological treatment of Alzheimer's disease. Curr neuropharmacol. 2010; 8(1): 69-80.

31. Lee SH, Bafna MR, Sancheti SS, et al. Acetylcholineterase inhibitory and antioxidant properties of Rhododendron yedoense var. Poukhanense bark. J med plants res. 2011; 5(2): 248-254.

32. Rahman MA, Uddin S, Wilcock C. Medicinal plants used by Chakma tribe in Hill Tracts districts of Bangladesh. Ind j tradit know. 2007; 6(3): 508-517.
33. Ploton L. From Hysteria to Alzheimer's Disease: The Function of the Symptom. Cliniques méditerranéennes. 2009; (1): 63-77.

34. Mathew M, Subramanian S. In vitro screening for anti-cholinesterase and antioxidant activity of methanolic extracts of ayurvedic medicinal plants used for cognitive disorders. PLoS one. 2014; 9 (1): e86804.

35. Bakhtiari M, Panahi Y, Ameli J, et al. Protective effects of flavonoids against Alzheimer's disease-related neural dysfunctions. Biomed pharmacother. 2017; 93: 218-229.

36. de Andrade Teles RB, Diniz TC, Pinto C, et al. Flavonoids as Therapeutic Agents in Alzheimer's and Parkinson's Diseases: A Systematic Review of Preclinical Evidences. Oxid med cell longev. 2018; 2018:1-21.

37. Airoldi C, La BF, D'Orazio G, et al. Flavonoids in the treatment of Alzheimer's and other neurodegenerative diseases. Curr med chem. 2018; 25: 3228-3246. 